\title{
Driven By Big Data: Are Our Students Prepared? Requiring Technology Coursework in University Sales Programs: An Abstract
}

\author{
Christine M. Kowalczyk and John Cicala
}

\begin{abstract}
The challenges faced by organizations trying to adopt and implement new technologies within their sales forces continue to grow, despite the widespread attention given to them by academics and practitioners. Increasingly sophisticated advances in hardware and software are creating unprecedented expectations and requirements for not only current salespeople but future selling professionals, too. This paper suggests current university-based sales programs may not be supplying their students with the applicable knowledge and skill sets related to sales technology they will need not only for their success but their employers' success as well.

The goal of this exploratory study was to identify how undergraduate students define sales and selling and to determine the positive and negative connotations associated with these terms among college students and their perceptions of technology in the sales profession. An online survey was created and distributed to a convenience sample of undergraduate students at universities located in the southeast and southwest United States for this purpose.

As the growth in opportunities in the sales profession is expected to increase, it is important for universities to understand how undergraduates view the sales profession as well as the need for technology in sales careers. Students perceive a strong need to understand current technologies associated with the sales profession. However, an initial review of existing sales programs in the United States indicates that such technologies may not be part of the curriculum.
\end{abstract}

References Available Upon Request

\author{
C.M. Kowalczyk $(\bowtie)$ \\ East Carolina University, Greenville, NC, USA \\ e-mail: kowalczyk@ecu.edu \\ J. Cicala \\ Texas A\&M University, Kingsville, TX, USA \\ e-mail: john.cicala@tamuk.edu
}

